\title{
DEHP Migration Behavior from Excessively Plasticized PVC Sheets
}

\author{
Jung Hwan Kim, Seong Hun Kim, Chang Hyung Lee, ${ }_{+}^{\dagger *}$ Jae-Woon Nah $\stackrel{+}{*}$ and Airan Hahn \\ Depatment of tiber \& Polymer Enginesing. Center for aldonced Hunctional tolvmers, \\ Hamang linversity, Seon 133-791. Lowea \\ Deparment of Medical Levices \& Radiation Healh. Rorea Food \& Drag Administration. \\ 5-iokben-dong, Eumpung-gu, Seoul 122-704, Korea

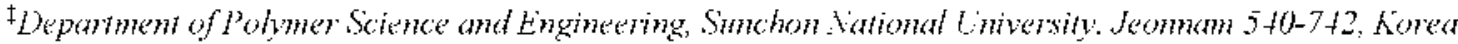

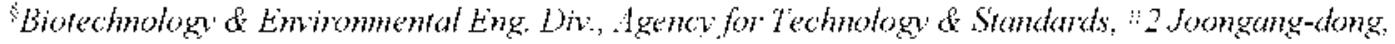 \\ Kuacheon Cin: Gyeonggido t27-716. Nowed \\ Received December 13,2002
}

\begin{abstract}
The quantity, process and kinetics of di-(2-ethy lhexyl)phthalate (DEI I') migration in the 30/70 and 40/60)


sheet was soaked in surrounding medium (SM) of water/ethanol mixture and acetonitrile with constant stirring to release DEI Il'. BY observed concentration of DEI I' in the SM, it is found that acetonitrile is more intense in DELII' migration than water/ethanol mixture. In addition the amount of extracted DEI I' is proportional to the leaching temperature and added ratio of DEIIP. The beharior of DEIII' migration from flexible P'VC sheets was described by the ricks's law with $2.72-10.1 \times 10^{113} \mathrm{~cm}^{2} / \mathrm{s}$ of the diffusion coefficients.
\end{abstract}

Key Words : Plasticizer migration, Di-(2-ethy lhexyl) phthalate, Poly (viny lehloride), Fickian beharior

\section{Introduction}

Poly(vinylchloride) (PVC) is one of the most widely used polymeric materials in the plastics industry. Phthalate ester. preferably di-(2-etly lhexyl) phthalate (DEHP), which is one of the well-known additives of rigid polymers, is particularly relevant to the various utilization of PVC articles. ${ }^{1-1}$ When DEHP is added to PVC resin. brittle PVC molecular chains become flexible, and thus the applications of PVC are extended. ${ }^{5}$

In the mean time, extensive studies have been carried out on the toxic materials with steady interests in the health. Among the typical toxic materials, endocrine disnuptors have attracted much attention as chemicals might disnupt the endocrine system. as it were. glands and honnones of humans and wildlife up to recently. DEHP become. unfortunately, surely revealed one of the endocrine disruptors producing adverse effect particularly in the liver and reproductive organs of mammals. ${ }^{3-8}$ Moreover it is so ubiquitous and widespread a material that it may be found in eatables and drinkables such as milk. cream. butter and cheese. ${ }^{6}$

Nonetheless remarkably serious toxicity of DEHP toward mankind and sarious kinds of animal are reported. DEHPplasticized PVC is widely used in medical and pharmaceutical applications such as packing materials. tubings. blood containers. catheters and so on because of low cost and absence of suitable altemations. ${ }^{1.35}$ In such applications. plasticized PVC may be in contact with various kinds of surrounding medium (SM) such as blood. artificial liquid medicine and chemical reagents. When DEHP-plasticized PVC articles keep in contact with a certain SM. DEHP may be leached from PVC articles into liquid medium. ${ }^{1.5 .1=-18}$ It is due to the fact that DEHP does not react with PVC molecules chemically, but permeate into PVC molecular chains to form a polar orientation. Moreover lipophilic characteristics of DEHP may operate as the driving force accelerating the migration phenomenon in substance.

Loss of plasticizer becomes very serious problem in the next two aspects: $:^{[1] 1 \cdot 1}$ First. The mechanical properties of polymer articles such as abrasive. compressive and tensile strength changes considerably, In addition. flexibility and transparency of polymers decrease to be useless in medical applications. Second. Extracted plasticizer may contaminate the surrounding medium (SM), to change them for toxic materials also.

Until now a large number of papers have been reported that DEHP migration phenomenon deeply relates to leaching solvent, i.e. SM..$^{1-3.11-18}$ However, no studies have been undertaken to investigate DEHP migration behavior from plasticized PVC articles including high ratio of DEHP into water/ethanol mixture and acetonitrile. Water/ethanol nixture is the only standard leaching solvent in the migration of DEHP from plasticized PVC bags specified by International Organization for Standardization (ISO) ${ }^{1 / 2}$ and acetonitrile is one of the most typical leaching solvent having powerful solubility due to its strong polar bonds in the molecular units. This paper is therefore undertaken in order to investigate plasticizer migration process and mechanism from DEHP-plasticized PVC sheets into two SM: water/ethanol mixture and acetonitrile. Because of no international regulations about the DEHP migration from PVC articles. there are numerous extracting and analytic methods in the DEHP migration. and in consequence. exist considerably different migrating results. ${ }^{1-3.141-18}$ In this situation. we will suggest a new extracting method of DEHP from plasticized PVC and discuss diffusion process and quantitative analysis. 


\section{Experimental Section}

Materials. Commercial-grade PVC straight resin powders with a 1.300 of degree of polymerization were obtained from Hanwha Chemical Co. DEHP. acetonitrile. methanol. ethanol and THF of ligh purity HPLC grade were altogether supplied commercially by Aldrich Chemical $\mathrm{Co}$. and used without further purification.

Flexible PVC sheets preparation. PVC plasticized with DEHP was prepared by extruding the two main components (PVC and DEHP) with a twin-screw extruder at about 130 C. then was cooled to room temperature and granulated to pellets. The compositions of the PVC/DEHP were $40 / 60$ and $30 / 70$ by weight. therefore we will confine the discussion to $30 / 70$ and $40 / 60$ PVC/DEHP blends. In order to remove the dusts and impurities on the surface of prepared pellets. the next washing methods were performed: The granulated pellets were soaked in $0.5 \%$ non-toxic neutral soap solution and thorouglly stimed for 3 minutes to be cleaned completely. Then the pellets were washed in rumning tap water for 5 minutes and finally rinsed with distilled water for another 10 minutes. The samples were then rinsed with HPLC grade methanol for 15 seconds and dried in an oven for 30 minutes at 50 " $\mathrm{C}{ }^{1}$ The washed pellets were molded in size of $20 \times$ $10 \times 0.4(\mathrm{~L} \times \mathrm{H} \times \mathrm{D})(\mathrm{mm})$ with using steel mold operated by a hot press at $170^{\circ} \mathrm{C}$. then quickly quenched to room temperature in a water bath. The prepared samples were again cleansed according to the above washing methods to purify the surface of sheets. Then the molded and rinsed PVC sheets were used for leaching. All the glasswares used in this study were thoroughly washed using THF-methanol mixture also.

Water/ethanol mixture preparation. Distilled water and ethanol were mixed thoroughly to prepare leaching solvent. The ratio of distilled water and ethanol was set to 123.77 $: 100$ by volume at 25 " $\mathrm{C}$ for adjusting the density of leaching solvent to be $0.9373-0.9378 \mathrm{~g} / \mathrm{mLL}^{169}$

Leaching and GC analysis. The prepared specimen was put into a volumetric flask ( $200 \mathrm{~mL}$ of capacity) filled with water/ethanol mixture or pure acetonitrile and stirred constantly: To preserve the internal stnicture of the samples. leaching temperatures above $60^{\circ} \mathrm{C}$ were not considered. After leaching. $2.0 \mathrm{~mL}$ of leaching solution was taken to analyze the DEHP content and another $2.0 \mathrm{~mL}$ of fresh solvent was quickly added.

The concentration of DEHP in the surrounding media was investigated using HP-5890 series 11 gas chromatograph equipped with a HP-5 capillary column characterized by 25 $\mathrm{m}$ of length and $0.2 \mathrm{~mm}$ of internal diameter. The thermal and operating information used in this chromatographic analysis is listed in Table 1.

\section{Results and Discussion}

Fick's law applied to one dimension may describe the leaching. transferring and diffusion phenomenon of relatively small molecules through flexible polymers. ${ }^{11 \cdot 13}$ In this
Table 1. The themal and operating information for the determitation of DF.HP

\begin{tabular}{|c|c|}
\hline \multicolumn{2}{|r|}{ Thermal information } \\
\hline Injector temp. & $230^{\circ} \mathrm{C}$ \\
\hline Detector temp. & $2600^{\circ} \mathrm{C}$ \\
\hline Analyzing temp. & $\begin{array}{l}\left.230^{\circ} \mathrm{C}(2 \mathrm{~min})-5^{\circ} \mathrm{Cm} \text { min }-250^{\circ} \mathrm{C} \text { (2 min }\right)- \\
1^{\circ \mathrm{C}} \mathrm{min}-255^{\circ} \mathrm{C}(5 \mathrm{~min})\end{array}$ \\
\hline \multicolumn{2}{|r|}{ Operating information } \\
\hline Column & $\begin{array}{l}\mathrm{IIP}-5 \\
(30 \mathrm{~m} \times 0.2 \mathrm{~mm} \text {. film thickness } 0.25 \mu \mathrm{m}, \\
\text { crosslinked } 5^{\circ} \text { o phenyl methỵl siloxame) }\end{array}$ \\
\hline Carrier gas & $\mathrm{N}_{2}$ \\
\hline Carrier gas llow rate & $28.6 \mathrm{ml}$ min \\
\hline $\mathrm{H}_{2}$ llow rate & $25.0 \mathrm{ml} \mathrm{min}$ \\
\hline Air flow rate & $300 \mathrm{mI}, \mathrm{min}$ \\
\hline Split ratio & $1000: 1$ \\
\hline 1)etector & lilame Ionization Detector \\
\hline
\end{tabular}

paper. following assumptions were made to explain the DEHP migration and diffusion appearance.

(a) PVC specimens in this paper are perfectly plane sheets whose thickness are $2 l$. The sheets are so thin that DEHP primarily migrates through the surface of sheets and release of DEHP through edge of the sheets is allowed to be neglect. ${ }^{11}$

(b) Diffusion coefficient is independent on concentration of DEHP. ${ }^{13}$

(c) The volume of leaching solvent is infinite compared with the amount of extracted DEHP. ${ }^{11.13}$

Under the previous assumptions. following equation is able to explain the migration process of DEHP from plasticized PVC sheets. ${ }^{11.12}$

$$
M / H_{\cdots}=2\left(D t / \pi t^{2}\right)^{1:-1}
$$

Where $1 / t_{t}$ and $1 / \%$ are the measured quantity of DEHP transferred at time $t$ and after infinite time, respectively: / is the thickness of specimen and $D$ is the diffusion coefficient unrelated to the DEHP concentration.... is determined to be a corresponding value at 50 days because some studies reported that the amount of extracted plasticizer does not shift significantly after 50 days. ${ }^{10.11 .13 .11}$

The cumulative amount of DEHP migration with leaching time at $40^{\circ} \mathrm{C}$ is illustrated in Figure 1 . In this Figure, $1 H_{\text {, }}$ value represents the concentration of DEHP in SM expressed in terms of $\mu \mathrm{g} / \mathrm{mL}$ and increases with time in initial stage. however tends to level off after 25 days in both curves. Furthermore it can be seen that the amount of migrating DEHP is affected by the nature of surrounding medium. When compared the two curves. DEHP migration into acetonitrile is more intense than in water/ethanol mixture.

It is worthwhile to investigate the relationship with $t^{1: 2}$ and M/M to explain the velocity of DEHP migration in the different surrounding media. In Figure 2. the functional relation of $t^{1: 2}$ and $H_{t} / M \ldots$, reveals a good linearity in the initial stage. This implies that DEHP migration from plasti- 



Figure 1. Changes of DF.HP migration against leaching time for water/ethanol mixtute and acetonitrile at $40^{\circ} \mathrm{C}$ : (a) I.eaching time of $1-2+$ hours: (b) $1-50$ day's.

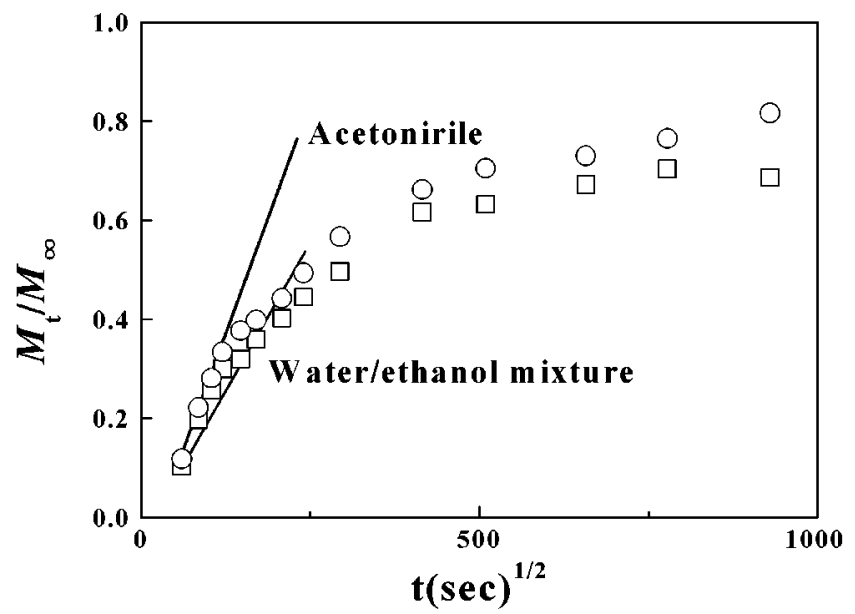

Figure 2. Changes of $M, A / \ldots$ against $t^{1:-}$ for the surrounding medium of water/ethanol mixture and acetonitrile at leaching temperature of $400^{\circ} \mathrm{C}$.

cized PVC sheets into surrounding medium can be described within the framework of the Fick's law. In addition the
Table 2. Diffusion coetficient data derived from the relationship hetween $D t / \pi t^{2}$ and $\left(M / A / . j^{2}\right.$ in various conditions

\begin{tabular}{cccccc}
\hline \multirow{2}{*}{$\begin{array}{c}\text { Sur rounding } \\
\text { medium }\end{array}$} & \multicolumn{5}{c}{$\mathrm{D}\left(\mathrm{cm}^{2} \mathrm{~s}\right) \times 10^{10}$} \\
\cline { 2 - 6 } & PVCDEHP & 3070 & & 4060 \\
\cline { 2 - 6 } & Temperature & $40^{\circ} \mathrm{C}$ & $300^{\circ} \mathrm{C}$ & $400^{\circ} \mathrm{C}$ & $600^{\circ} \mathrm{C}$ \\
\hline Water ethanol mixiture & 8.29 & 2.72 & 4.77 & 10.1 \\
Acetonitrile & 7.70 & 4.68 & 5.75 & 6.79 \\
\hline
\end{tabular}

modulus of the straight line is closely connected with the diffusion coefficient of the DEHP migration in this system. ${ }^{11.13 .1-1}$ The diffusion coefficients will be discussed in Table 2. On the other hand. the rates of increase have slowed gradually according to the $t^{\mathrm{s}}$ in the middle stage of the graphs. This appearance may be explained to the counterdiffusion. i.e. penetration of the surrounding media into PVC sheets. "' After DEHP molecules gradually moved into SM. surrounding media slowly filled the vacant place of PVC sheets. In the initial stage. permeation of the DEHP from $\mathrm{PVC}$ sheets into surrounding medium actively takes place, however the rate of DEHP migration from sheets may decrease when a temporary equilibrium of DEHP concentration in the PVC sheet and surrounding medium is reacled
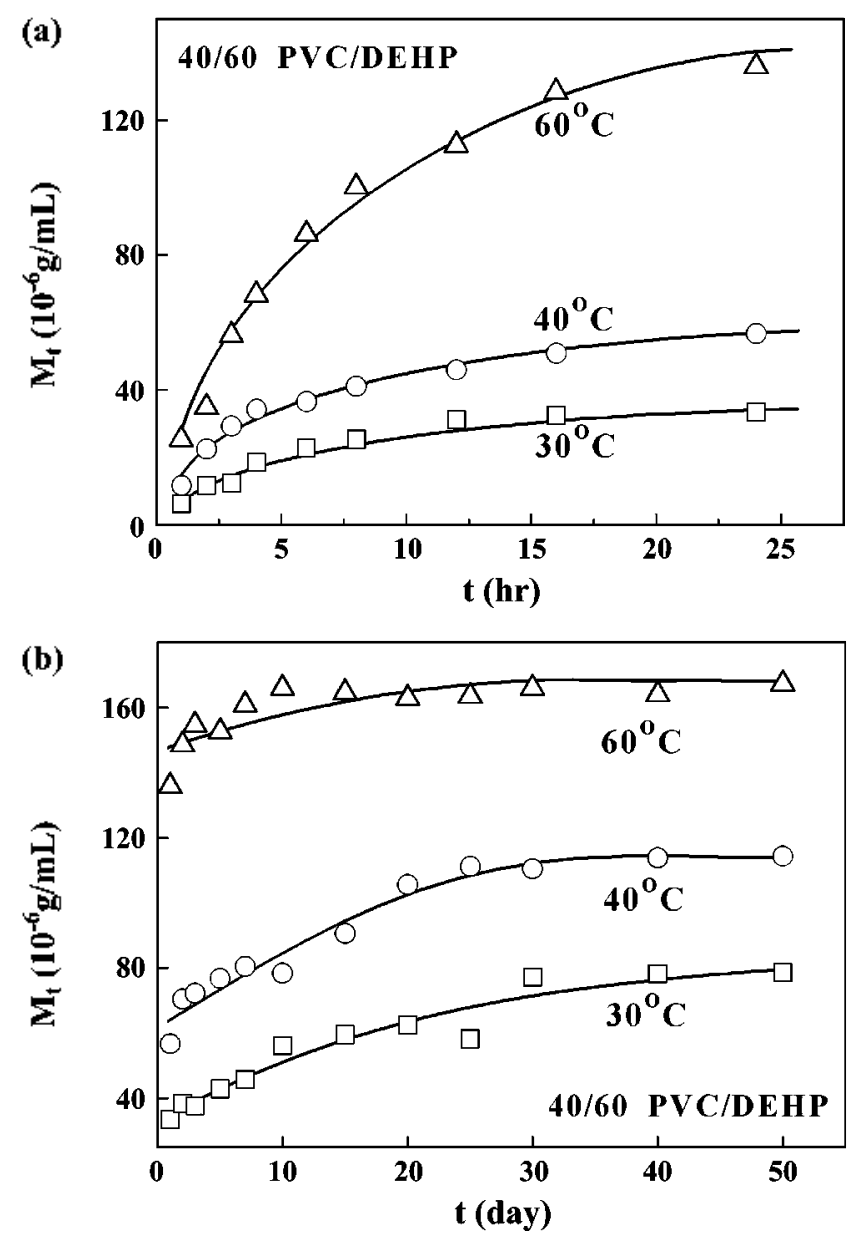

Figure 3. Plots of DEIP migration against time for surrounding medium of water/sthanol mixiure at three temperature: 30.40 and $60^{\circ} \mathrm{C}$. T.eaching time is (a) $1-24$ hour and (b) $1-50$ day: 

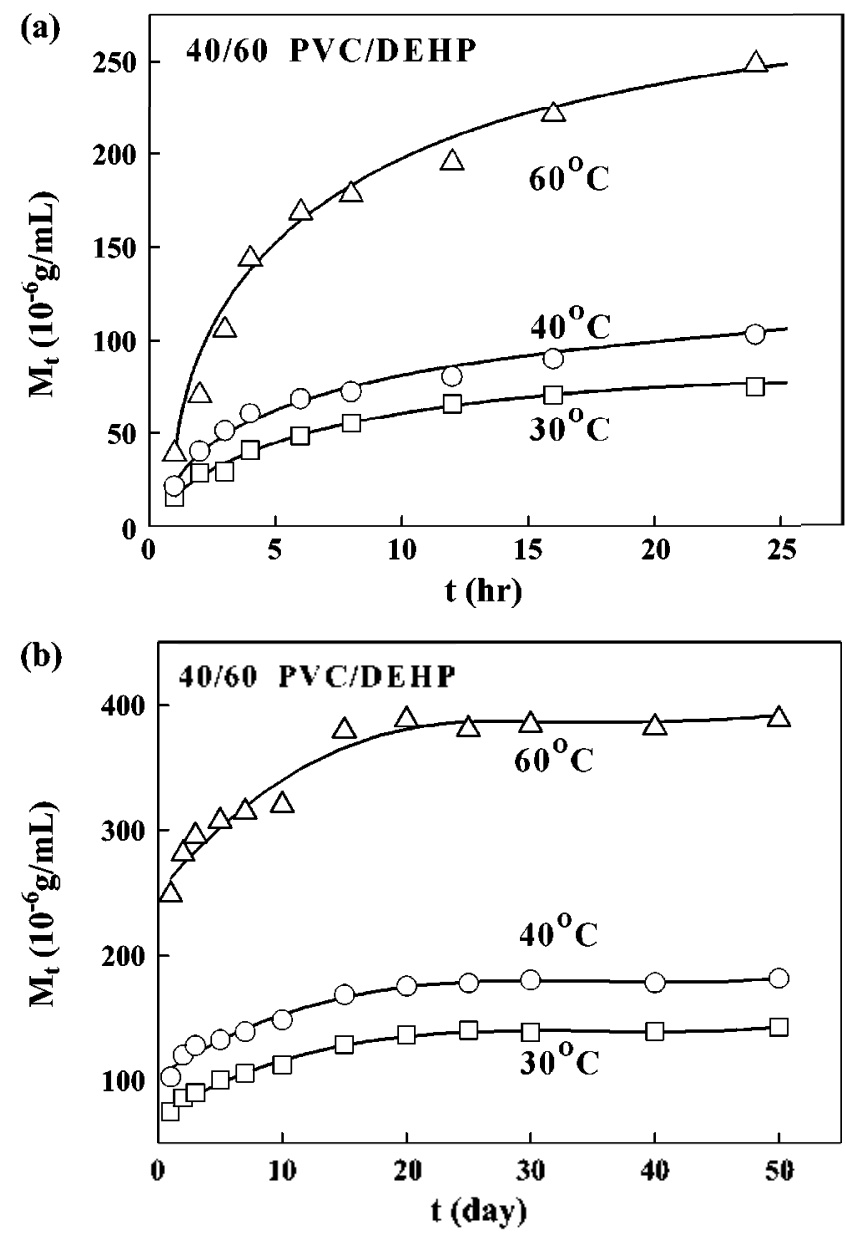

Figure 4. DLII migration against time for surrounding medium of acetonitrile at three temperatures: 30,40 and $60^{\circ}$ "C. Leaching time is (a) $1-24$ hout's and (b) $1-30$ days.

due to the counterdiffusion.

According to the previous papers reported plasticizer migration from PVC articles. diffusion coefficient $D$ is dependent on the nature of surrounding media and leaching temperatures. ${ }^{1011.13 .14}$ Then we investigated the amount of DEHP migration into SM at different temperatures. Figure 3 shows the quantity of DEHP migration for SM of water/ ethanol mixture at 30.40 and $60 \mathrm{C}$. As illustrated. $H_{\text {, steeply }}$ increased at initial period and then gradually to equilibrium. Furthermore the time, in which $I_{s}$ arrived at plateant. decreased with increasing temperature. It suggests that DEHP leaching takes place very intensively at early stage in high temperature. and thus diffusion coefficient at high temperature is higher than that at low temperature in water/ethanol mixture.

Figure + represents the corresponding plot of DEHP migration for SM of acetonitrile at three temperatures. The behavior in acetonitrile is quite similar to that in water/ ethanol mixture. From this, it can be concluded that DEHP leaching mostly happens at initial stage regardless of the leaching medium and equilibrium reaches earlier at high temperature. If we take into account that the disparity of DEHP concentration between PVC sheet and SM powerfully operates upon the diffusion rate. fast attainment of equili-
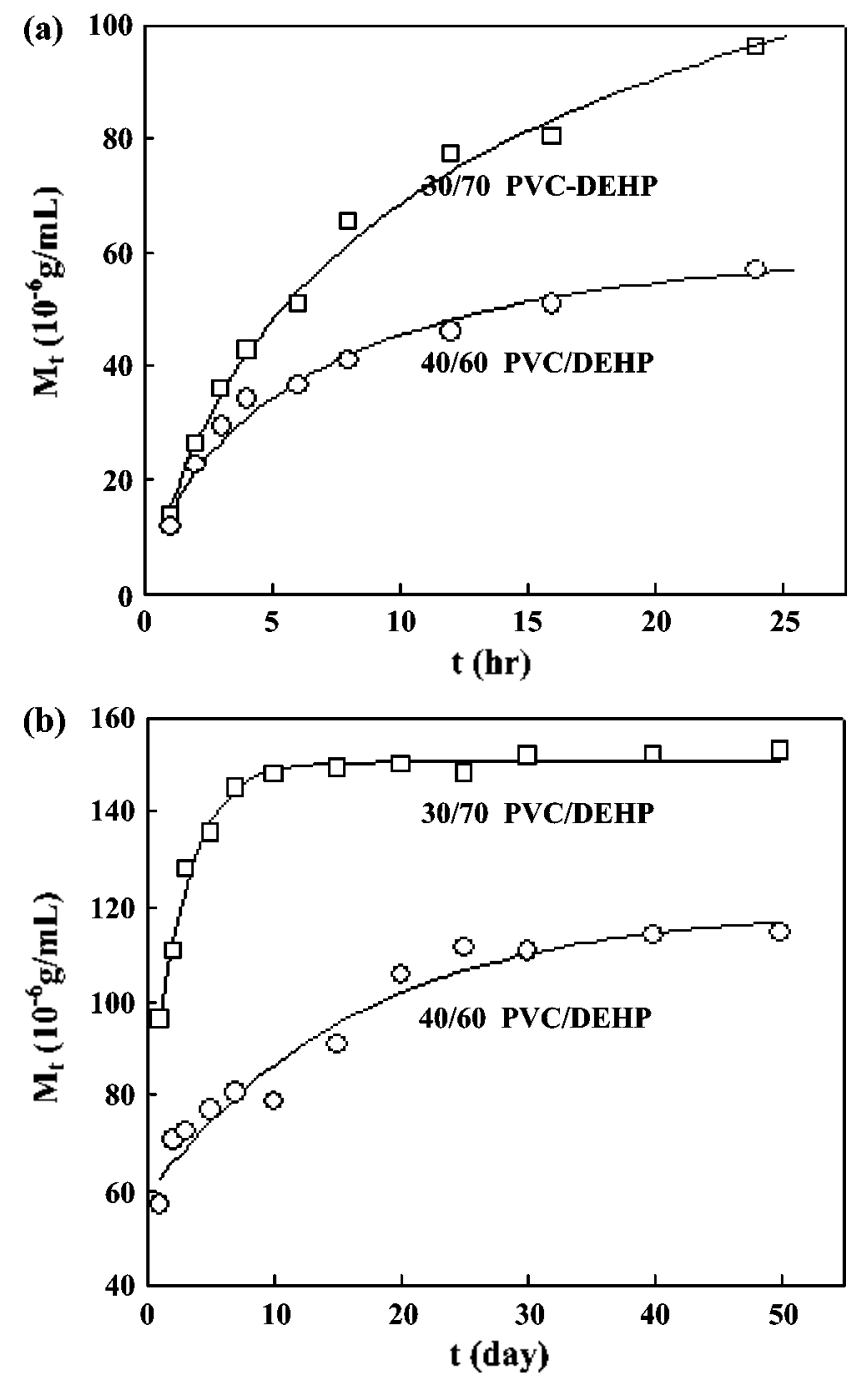

Figure 5. Plots of DEIP migration against time for surrounding medium of water/ethanol mixture at $40{ }^{\circ} \mathrm{C}$. Initial plasticizer concentrations is $60 \mathrm{wt} \%(0)$ and $70 \mathrm{nt} \%(\mathrm{l})$ respectively and laching time is (a) 1-24 hours and (b) 1-50 days.

brium in migrating DEHP may represent the increasing of diffusion coefficient.

ln order to investigate the effect of DEHP concentration on migration process in water/ethanol mixture, the levels of DEHP leaching for the blends of $40 / 60$ and $30 / 70 \mathrm{PVC} /$ DEHP are observed. These results are presented in Figure 5. For both blends the $h_{f}$ values steeply increase at initial period and then level off. suggesting that migration of DEHP mostly takes place at initial stage regardless of the amount of added DEHP. The leaching behavior of DEHP at early stage is similar to that discussed in Figure 3 and 4 . But. there is a significant difference between two samples. The $1 / H_{i}$ values in $+0 / 60$ blend increase during early stage and are kept in low values. This means that DEHP is well trapped in the sample. In 30/70 PVC/DEHP blend. the $1 /$, values steeply increase and then level off in high values. It is believed that DEHP is not enclosed inside the sample. The larger the amount of DEHP, the more intensively DEHP migration takes place. This phenomenon can be explained that DEHP 



Figure 6. Plots of DF.HP migration against time for surrounding medium of acetonitrile at 40 " $\mathrm{C}$. Initial plasticizer concentrations is $60)+1 \%(0)$ and 70 w1\%( $\sqsupset)$, respectively, and leaching time is (a) $1-24$ hout and (b) $1-50$ day.

permeates into the space of PVC molecular chains when the main two materials. PVC and DEHP, are mixed. Intramolecular interaction between the polymer chains decreases with increasing DEHP. and consequently the whole bonding force decreases to release more DEHP from PVC matrix. The corresponding result in acetonitrile is presented in Figure 6. The result of such tendency is shown in Figure 4. suggesting that the leaching behavior of DEHP is independent of leaching medium.

Finally Diffusion coefficient $D$ is calculated and discussed on the basis of the previous results. According to eq. $\mathrm{L}$. a plot of $: 1 / \mathrm{d} / \mathrm{M}$ versus $t^{1: 2}$ should yield a straight line of slope $2(\mathrm{D})$ $\left.\pi l^{2}\right)^{1: 2}$. The linear releationship at early stage is realized for water/ethanol mixture and acetonitrile at $40{ }^{\circ} \mathrm{C}$ as shown in Figure 2. indicating that the initial stage can be described by the linerarized theory. From the value of $2\left(D / \pi l^{2}\right)^{1: 2}$, one can obtain the diffusion coefficient $D$. The results are shown in Table 2. The variation in the tendency of plasticizer to migrate with respect to various conditions is clearly displayed. As expected, one can see that with increasing temperature and added amount of DEHP. $D$ value increase. In addition. $D$ in acetonitrile is ligher then that in water/ethanol mixture. The high and low $D$ values correspond to the large and small amount of DEHP leaching. respectively. This implies that DEHP intensively migrate to SM of acetonitrile.

\section{Conclusions}

From the experimental results the following conclusions can be drawn:

1. DEHP migration from plasticized PVC sheets is controlled by the Fickian diffusion behwvior. In other words, when diffusion coefficient is relatively high. DEHP migrates into SM actively. Therefore the assumptions of the Fick's law can be applied to DEHP-plasticized PVC thin sheets.

2. The release behavior of DEHP from flexible PVC sheet is affected by the nature of surrounding medium. Namely, DEHP nugration is more intense in acetonitrile than in water/ ethanol mixture: at the early stage than at any other stages. Diffusion coefficients of DEHP through flexible PVC sheets in various conditions are $2.72-10.1 \times 10^{-11} \mathrm{~cm}^{2} / \mathrm{s}$ and dependent on the quantities of initial migration.

3. DEHP migration is generally proportional to the leaching temperature and the amount of added DEHP. When leaching temperature or the added DEHP is high. extracted DEHP increases as well as.

\section{References}

1. Jasakrishnan. A.: Sunny, M. C. Polvmer 1996. 37, 5213.

2. I.junggren, J ... intif. Organs. 1984, 8,99.

3. Kambia, K.: Dine, T.A Azar. R.: Gressier, B.: I.urckx. M.: Bunct, C. Int J. Hham 2001. 229. 139.

4. Parmar. D.: Srivastava. S. P.: Singh. G.: Seth. P. K. I'tf. Homam Foricol 1995 . 34.310.

5. Jacobson, M. S.: Kery, S. V.: Parkman. R.: Wesolonsti. I. S. Transfusion 1980. 20. 443.

6. Sliarman, M.: Read, W. A.: Castle, I.: Gilbert. J. Food . Iddht. Contam. 1994. 11. $37 \overline{5}$.

7. Tomita. I.: Nakamura. Y.: Yagi. K.: Tulikawa. K. Emirom. Healh fersp. 1982. 45.71 .

8. I.i, I.. H.: Icster, W. F.: Orth. J. M. Toxicol .tppl Pharm. 1988. 153,258 .

9. Guillette. I.. I.: Pichtord. D. B.: Crain. D. A.: Romer, A. A.: Percival. H. F. Gem. Comp. Endocr. 1996. 101. 32.

10. Messadi. D.: Verenaud. J. M. J. Appl. Polvm. Sci. 1982. 27. 3945.

11. Papaspyrides. C. D. J. Appl. Potym Sci. 1992. 4.1145.

12. Steiner', I.: Schart, I .: Fiala, Г.: Washuttl, I. Food Lddit. Contan. $1998,15,812$.

1.3. Papaspirides, C. D.: Duvis, T. Polvmer 1990, 3/, 1085.

14. Messadi. D.: Vergnaud. J. M. J. Appl. Polym. Sci. 1981. 26. 2315.

15. Labow. R. S.: Tocchi. M.: Rock. G. Tronsfusion 1986. 26. 351.

16. Rastogi. S. C. Chromologrophia 1998. 77.724.

17. Dine, T.: Juyckx, M:Cazin, M: Brunet. C.: Cazin, I. C.: Goudaliez. F. Biomed Chromatogr. 1991, 5.94.

18. Fayz. S.: I Icrbert, R.: Martir, A. d. Pharm. Pharmac. 1977, 29. 407.

19. ISO j\$26. "Pastics Collapsible Containers for Human Blood and Blood Components". 1993. 